\title{
Synergistic Interactions of D1- and D2-Selective Dopamine Agonists in Animal Models for Parkinson's Disease: Sites of Action and Implications for the Pathogenesis of Dyskinesias
}

\author{
H.A. Robertson
}

\begin{abstract}
The addition of a D2 agonist such as bromocriptine to L-Dopa therapy can often improve the response of patients with Parkinson's disease dramatically. Simultaneous activation of DI and D2 dopamine receptors can produce a synergistic effect on locomotion in rats and primates. However, despite the importance of this addition of a D2 agonist to the D1/D2 agonist L-Dopa, little is known of the sites of action of these agents. Recent work suggests that, in addition to D1 and D2 dopamine receptor sites in the striatum (caudate-putamen), L-Dopa and D1 agonists have important effects at D1 dopamine receptors in the substantia nigra. Animal experiments suggest that DI and D2 dopamine receptor agonists probably also affect different outflow pathways from the striatum. An understanding of these pathways and how dopamine agonists affect them gives insight into some of the clinical problems experienced in treating Parkinson's disease (the "on-off" phenomenon, for example). DI/D2 dopamine receptors also differentially affect gene expression and regulation in the striatum. An understanding of the anatomical and biochemical location of the actions of dopamine receptor agonists will be important in maximizing the beneficial effects and minimizing the side-effects of both presently-used drugs and new treatments.

RÉSUMÉ: Interactions synergiques des agonistes dopaminergiques sélectifs pour D1 et D2 chez les molèles animaux de la maladie Parkinson: site d'action et implications pour la pathogenèse des dyskinésies. L'addition d'un agoniste D2 tel la bromocriptine à la L-dopa thérapie peut souvent améliorer dramatiquement la réponse thérapeutique des parkinsoniens. L'activation simultanée des récepteurs dopaminergiques D1 et D2 peut produire un effet synergique sur la locomation chez les rats et les primates. Cependant, malgré l'importance de cette addition d'un agoniste D2 à l'agoniste DI/D2 qu'est la L-dopa, on connaît peu de choses sue les sites d'actions de ces agents. Des études récentes suggèrent que, en plus des sites des récepteurs dopaminergiques D1 et D2 dans le striatum (putamen-noyau caudé), la L-dopa et les agonistes Dl ont des effets importants sur les récepteurs dopaminergiques Dl dans la substance noire. L'expérimentation animale suggère que les agonistes des récepteurs dopaminergiques D1 et D2 affectent aussi probablement différentes voies efférentes du striatum. La compréhension de ces voies et de la façon dont les agonistes dopaminergiques les influencent éclairent les problèmes cliniques rencontrés dans le traitement de la maladie de Parkinson (par exemple, le phénomène "on-off"). Les récepteurs dopaminergiques D1/D2 influencent de façon différentielle l'expression et la régulation génique au niveau du striatum. La compréhension du site anatomique et biochimique d'action des agonistes des récepteurs dopaminergiques sera importante pour maximiser les effets bénéfiques et minimiser les effets secondaires des médicaments présentement utilisés et des nouveaux traitements.
\end{abstract}

Can. J. Neurol. Sci. 1992; 19:147-152

L-Dopa continues to be the most effective treatment for Parkinson's disease. It is now also generally accepted that dopamine formed from L-Dopa exerts its clinical effects via activation of at least two subtypes of dopamine receptor, DI and D2.' While there is now good evidence for a D3 dopamine receptor as well, relatively little is known about the role of this receptor at present. ${ }^{2}$ For a number of years now, there has been good evidence to suggest that D1 and D2 receptor mechanisms relate to different output pathways of the striatum, and while there is a certain similarity in action (in both animal models and

From the Departments of Pharmacology and Medicine (Neurology), Faculty of Medicine, Dalhousie University, Halifax

Reprint requests to: H.A. Robertson, Departments of Pharmacology and Medicine, Faculty of Medicine, Dalhousie University, Halifax, Nova Scotia, Canada $\mathrm{B} 3 \mathrm{H} 4 \mathrm{H} 7$ 
man) between D1 and D2 dopamine agonists, there are, however, also marked differences as well. Furthermore, it seems clear that D1 and D2 dopamine agonists interact synergistically, again in both animal models of Parkinson's disease and possibly in the disease itself, to produce movement and relief from the symptoms of Parkinson's disease. Although L-Dopa is the most effective treatment for Parkinson's disease, it is far from ideal. After several years of good effect, management becomes complicated by fluctuations in motor response and the development of involuntary movements. Recent evidence suggests that knowledge of the sites of action of D1 and D2 agonists in Parkinson's disease and the different effects mediated by these two receptor types might contribute much to an eventual resolution of these therapeutic problems. An important part of my premise is that much of the effect of L-Dopa may be mediated not by striatal dopamine receptors but by DI dopamine receptors in the substantia nigra pars reticulata. Finally, we now know that the stimulation of dopamine receptors can activate gene expression in striatum, raising the possibility that these alterations in gene expression might lead to the complications that severely compromise the long-term use of L-Dopa. A clear understanding of these mechanisms could be the first step in developing therapies which will produce less fluctuation and fewer side effects.

To understand L-Dopa's actions in Parkinson's disease, it is necessary to unravel the actions of D1 agonists, D2 agonists and the combination of D1 and D2 agonists in the condition of severe loss of dopamine neurons. The interactions of D1 and D2 receptors must then be understood in the anatomical context of receptor localization, first within a brain region (striatum, for example) and then within a system involving several regions (the nigrostriatal system, for example). The clearest picture to date has been obtained from studies on rats with unilateral 6 hydroxydopamine (6-OHDA) lesions (the Ungerstedt model). ${ }^{3}$

\section{The Substantia Nigra as a Site of Action of L-Dopa}

Since the discovery that L-Dopa was effective in Parkinson's disease, it has been tacitly (and not unreasonably) assumed that the site of action of L-Dopa is the striatum, the region of the forebrain innervated by terminals of the dopamine-containing neurons. However, to understand the actions of neurotransmitters and their receptors in the brain, and the drugs which act at these receptors, it is now clear that we must understand precisely where in the brain a drug (or transmitter) is working and this then requires that we know where receptors and receptor subtypes are distributed in the brain. This is very well demonstrated by the case of dopamine where there are at least three types of dopamine receptor and these can be located either postsynaptically or presynaptically. Another most important feature of dopamine is that it is released not only from axon terminals but also from dendritic terminals. ${ }^{4}$ Figure 1 summarizes the location of D1 and D2 dopamine receptors on efferent pathways of the striatum and in the substantia nigra.

It has been known for some time that dopamine-containing neurons of the substantia nigra release dopamine from both the terminals in the striatum and from the dendrites in the substantia nigra pars reticulata. ${ }^{4}$ When the dopamine neurons are lost (as happens in Parkinson's disease) or are destroyed by neurotoxins such as 6-OHDA or 1-methyl-4-phenyl-1,2,3,6-tetrahydropyridine (MPTP), D2 dopamine receptors in the substantia nigra dis- appear because the D2 receptors appear to be entirely confined to the dopamine neurons (Figure 2). ${ }^{5.6}$ However, DI receptor density in the substantia nigra pars reticulata, which is as high as the D1 receptor density in the striatum (the highest in the brain), ${ }^{7}$ is unaffected by such dopamine neurotoxin lesions ${ }^{8}$ because the D1 receptors are on the terminals of descending striatonigral fibres. These Dl receptors become supersensitive, presumably because they are no longer stimulated by dopamine released from dopaminergic neurons in the substantia nigra (see Figure 2). ${ }^{9}$ Thus in the animal models for Parkinson's disease, there is a greatly enhanced receptor sensitivity of D1 receptors in the substantia nigra while nigral D2 dopamine receptors are lost in proportion to the severity of the disease.

Paradoxically, it has been apparent for some time that D1 and D2 dopamine agonists interact in either an additive or a synergistic fashion in animal models for Parkinson's disease ${ }^{10-13}$ but when biochemical parameters (such as adenylyl cyclase activity, for example) are studied, D1 and D2 agonists have opposing actions (for reviews). ${ }^{14-16}$ Faced with this paradox, we proposed that a part of the explanation might be that D1 and D2 dopamine receptors might have separate sites of action. ${ }^{14,15}$ We further suggested that some of these sites of action might be anatomically separate and distinct, with Dl agonists having important actions in the substantia nigra pars reticulata as well as in the striatum. ${ }^{14.15}$

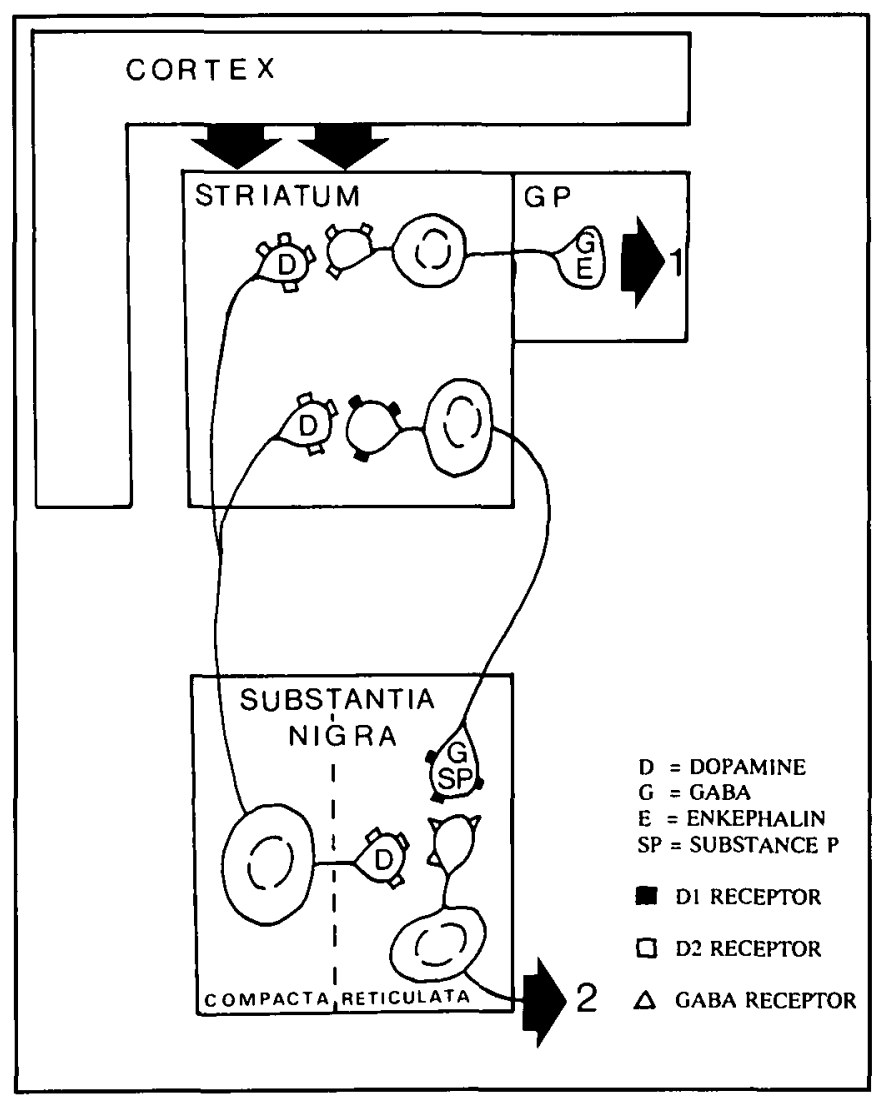

Figure I - Schematic representation of location of DI and D2 dopamine receptors within the nigrostriatal system and their relationship to the striatopallidal' or striatonigrat output pathways. GP. globus pallidus. 
Considerable direct and indirect evidence now supports the contention that D1 and D2 agonists produce their potent synergistic effects in animal models for Parkinson's disease by actions in both striatum and substantia nigra. For example, prevention of decarboxylation in the substantia nigra, by injection of the L-Dopa-decarboxylase inhibitor carbidopa directly into the substantia nigra, will prevent L-Dopa-induced rotation in rats with a unilateral 6-OHDA lesion of the substantia nigra. ${ }^{17}$ Dopamine formed from circulating L-Dopa presumably acts to increase neurotransmitter (GABA) release via supersensitive D1 receptors on presynaptic $\mathrm{GABA} / \mathrm{SP} /$ dynorphin neuron terminals in the substantia nigra pars reticulata. Carbidopa prevents LDopa from being decarboxylated to dopamine and thus any action on dopamine receptors is prevented. Similarly, SCH 23390 infused directly into the substantia nigra prevents the dopamine formed from L-Dopa from exerting any effect by blocking D1 receptors. ${ }^{18}$

Electrophysiological studies also suggest that D1 dopamine receptor activation decreases cell firing rates in the substantia nigra pars reticulata, presumably by increasing release of GABA from the terminals of striatonigral fibres. ${ }^{19}$ This idea has recently been confirmed in studies on release of ${ }^{3} \mathrm{H}-\mathrm{GABA}$ from slices of substantia nigra. In nigral slices, L-Dopa-induced release of ${ }^{3} \mathrm{H}-\mathrm{GABA}$ is prevented by the DI antagonist $\mathrm{SCH}$ 23390 but is unaffected by the D2 antagonist sulpiride. ${ }^{20}$ The

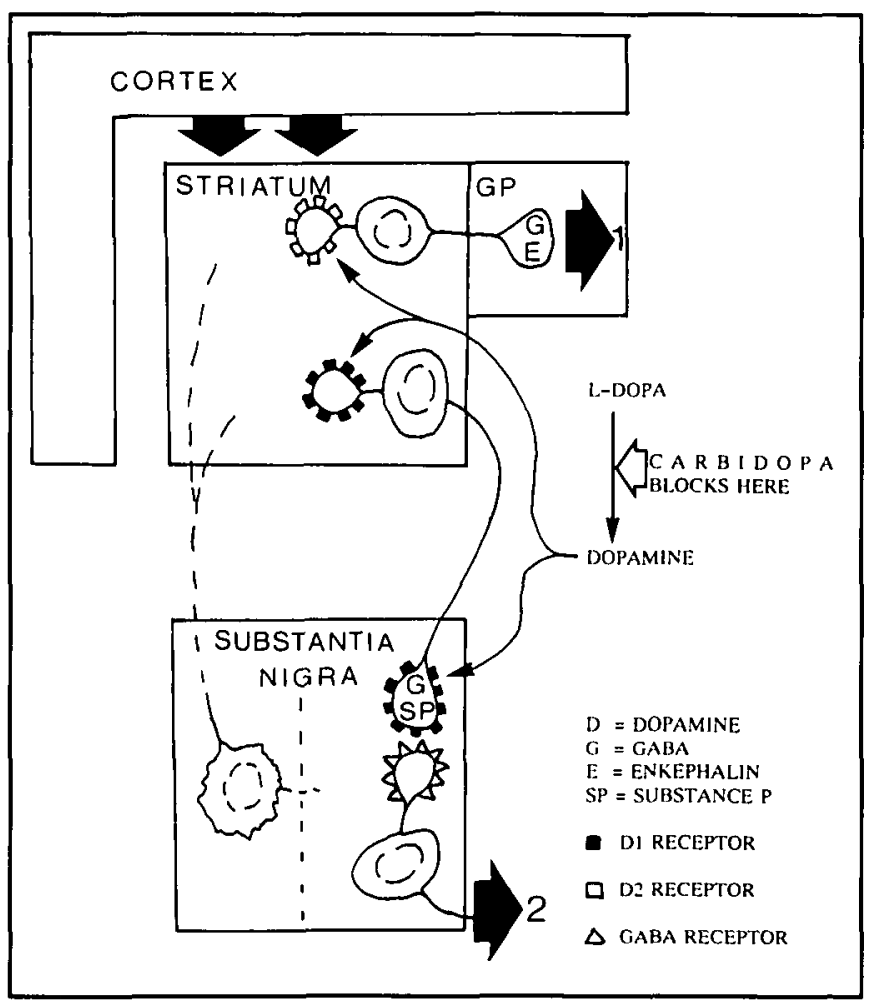

Figure 2 - Schematic representation of location of DI and D2 dopamine receptors within the nigrostriatal system and their relationship to the striatopallidal' or striatonigral ${ }^{2}$ output pathways after loss of the dopamine neurons. Both DI and D2 dopamine receptors proliferate (Figure 1) to compensate for loss of dopamine. Note that D2 dopamine receptors disappear completely from the substantia nigra. Dopamine formed from L-Dopa acts at both types of dopamine receptor. GP, globus pallidus. conclusion that L-Dopa is acting in the substantia nigra is also corroborated by 2-deoxyglucose uptake studies ${ }^{21}$ which show a dramatic effect of D1 (and L-Dopa) but not a D2 dopamine agonist on neuronal terminals in the substantia nigra on the lesioned side in 6-OHDA lesioned rats.

While this review has emphasized the role of the substantia nigra in the actions of L-Dopa and dopaminergic agonists, this is not intended to depreciate the actions of L-Dopa in the striatum where after all, dopamine levels are at least an order of magnitude higher. However, realization that D1/D2 synergistic interactions in the Ungerstedt model occur at the level of the striatum has been seriously questioned by both electrophysiological and behavioral studies. White and his colleagues ${ }^{22}$ have shown in electrophysiological experiments that the requirement for DI receptor stimulation for D2-mediated effects, in this case inhibition of cell firing in striatum, is found in naive rats but not in animals with 6-OHDA lesions. ${ }^{22}$ The idea that D1 and D2 agonists might interact within the 6-OHDA-lesioned striatum has also been questioned in behavioral experiments in which both quinpirole and SKF 38393 were injected directly into striatum..$^{23}$ The effect of intrastriatal quinpirole on rotation was not enhanced by intrastriatal DI agonist. Rotation induced by systemic SKF 38393 is blocked by intranigral SCH 23390, in agreement with our results. ${ }^{18}$ However, intranigral injection of the D2 selective antagonist eticlopride do not prevent the effects of systemic SKF $38393 . .^{23}$

Other crucial support for the idea that L-Dopa has important effects in the substantia nigra comes from studies on the time course of L-Dopa's effects in the Ungerstedt model.

\section{The Time Course of L-Dopa Actions}

Studies on the production of dopamine in striatum following systemic injections of L-Dopa had previously revealed a time course that did not explain the behavioral effects. ${ }^{24}$ The behavioral effects of L-Dopa in rats with a unilateral 6-OHDA lesion persist for almost exactly four hours but the increase in dopamine levels in striatum only lasts about 90 minutes. ${ }^{24}$ There is also a poor correlation between the extracellular concentration of dopamine (measured using brain microdialysis) and rotational behavior..$^{25}$ It therefore seemed likely that if the time course of dopamine formation or extracellular dopamine in striatum did not reflect the time course of L-Dopa's behavioral effects, then the time course of dopamine formation from L-Dopa in some other brain region might be more reflective of the behavioral consequences; this in fact proved true for the substantia nigra. ${ }^{18}$ A single injection of L-Dopa produces increases in striatal dopamine for only about two hours but rotation continues for four hours (as Spencer and Wooten ${ }^{24}$ have found). However, clevations in dopamine in the substantia nigra persist for four hours and when they fall to control levels, rotation also ceases. ${ }^{18}$ Importantly, both systemic and direct intranigral administration of the D1-selective receptor antagonist SCH 23390 prevents this L-Dopa-induced rotation. ${ }^{18}$ This and other work ${ }^{17,211}$ provide strong support for the contention that L-Dopa is converted to dopamine in the substantia nigra and, furthermore, the dopamine formed there produces effects that are clearly essential for the expression of rotation in this animal model of Parkinson's disease. Since we know that nearly all of the D1 dopamine receptors in the substantia nigra are presynaptic on terminals of descending striatonigral fibres, ${ }^{8}$ it seems clear that 
this is the site of L-Dopa's actions within the substantia nigra. Finally, the effects of L-Dopa in the substantia nigra are apparently of longer duration than those in the striatum. This may therefore have very important clinical consequences.

The conclusion that D1 agonists were acting at least in part on Dl receptors on terminals of striatonigral fibres in the substantia nigra pars reticulata appears then to be irrefutable. However, there is still some doubt as to the other sites of action of L-Dopa and dopaminergic agonists. Some light has been shed on this recently by the finding that Dl receptors in the striatum are largely located on neurons of the striatonigral pathway while D2 receptors are largely found on striatopallidal efferents.

\section{D1 and D2 Pathways From the Striatum}

Herrera-Marschitz and Ungerstedt ${ }^{26.27}$ clearly showed that the characteristics of the rotation exhibited by rats in the Ungerstedt model was dependent on whether the eliciting drug acted primarily at D1 or at D2 receptors. Moreover, the behavioral differences appeared to reflect a difference in the outflow pathway. Turning produced by apomorphine was characterized by a "two-peak" pattern, with conspicuous gnawing and biting and a "tight rotation" where the animal appears to be chasing its tail. Apomorphine, a mixed D1/D2 agonist, induced turning that was blocked by the mixed D1/D2 antagonist cis-flupenthixol and, most importantly, was completely eliminated by a kainic acid lesion to the already 6-OHDA lesioned substantia nigra. ${ }^{26,27}$ On the other hand, pergolide, a nearly pure D2 agonist, produced turning characterized by a "one-peak" turning pattern, less tight rotation and less oral stereotypies. Significantly, the turning induced by pergolide was not blocked by kainic acid lesions and, furthermore, was antagonized by the D2 selective antagonist at $1 / 1000$ the dose required to eliminate apomorphine induced turning. Herrera-Marschitz and Ungerstedt ${ }^{27}$ concluded that apomorphine has its main effect via a D1 dependent pathway going from striatum to the substantia nigra (the striatonigral pathway). Pergolide or D2-induced turning depends mainly on what they described as "other efferent pathways". We now appreciate that information flows out from the striatum either via the well-known striatonigral pathway or via a pathway leading via the globus pallidus to the thalamus and then to cortex (Figure 1). ${ }^{28}$ Recent studies using oligonucleotide cDNA probes for D1 and D2 receptor "RNA combined with fluorogold tracktracing techniques have now shown that DI dopamine receptors are for the most part located on striatonigral projecting neurons while D2 dopamine receptors are located on striatopallidal neurons. ${ }^{29}$ These findings agree well with the predictions of Herrera-Marschitz and Ungerstedt ${ }^{26.27}$ and with the observation that dopaminergic nigrostriatal neurons appear to express D2 dopamine receptors on both the perikarya and terminals in the striatum and striatonigral neurons express D1 receptors on both the perikaraya (in striatum) and terminals in substantia nigra pars reticulata (see Figures $I$ and 2 ). The peptide neurotransmitters or co-transmitters in the pathways from striatum to substantia nigra and globus pallidus are known, enkephalin containing GABAergic neurons extending to globus pallidus and substance $P$ and/or dynorphin-containing GABAergic neurons innvervating the substantia nigra (Figure 1$).^{28}$ In rats with unilateral 6OHDA lesions, three weeks of intermittent (but not chronic) Dl agonist treatment (SKF 38393) increases both the mRNA for substance $\mathrm{P}$ and dynorphin on the lesioned side. ${ }^{29}$ Dynorphin
mRNA levels are dramatically elevated. ${ }^{29}$ On the other hand, continuous but not intermittent D2 agonist treatment with quinpirole decreases enkephalin mRNA and D2 dopamine receptor mRNA on the lesioned side. In other words, intermittent DI agonist treatment affects the striatonigral pathway while chronic D2 agonist treatment affects the striatopallidal pathway. It is interesting and probably of great clinical importance that, in MPTP-treated monkeys, D1 agonist treatment but not D2 agonist treatment is associated with the development of dyskinesias. ${ }^{31}$

\section{Clinical Implications}

It is not yet possible to test directly whether the dramatic increase in dopamine in the substantia nigra following L-Dopa administration seen in rats is also seen in human Parkinson's disease. As the resolution for PET scanning precludes (at present) study of areas as small as the substantia nigra in man in vivo, this question cannot be addressed directly at this time. However, recent clinical studies have suggested that postsynaptic modifications in unspecified sites may contribute to the motor fluctuations ("on-off effects") so frequently seen in patients who have been treated with L-Dopa for some time..$^{31.32}$ Weick and his colleagues ${ }^{33}$ have shown that intermittent L-Dopa treatment in rats with unilateral 6-OHDA lesions of the nigrostriatal pathway will diminish the effects of the DI agonists SKF 38393 on the firing rate of substantia nigra pars reticulata neurons. This treatment also reverses lesion-induced supersensitivity to iontophoresed GABA. In contrast, continuous L-Dopa administration (via osmotic minipumps) produces neither of these effects. ${ }^{3,3}$ This suggests that it is the repeated fluctuations in L-Dopa levels and not merely chronic exposure to L-Dopa that produce changes in the effects of dopamine (via D1 receptors) and GABA on substantia nigra pars reticulata neurons. These findings support the idea that intermittent L-Dopa after lesions of the nigrostriatal pathway (which every Parkinson's disease patient taking L-Dopa experiences) may produce postsynaptic changes in downstream sites such as the substantia nigra. ${ }^{31.32}$ In support of this, it is known that motor fluctuations ("on-off phenomena") in patients with Parkinson's disease diminish in response to continuous L-Dopa infusion. ${ }^{31}$ Weick et al. ${ }^{33}$ proposed that this diminution in motor fluctuations may be at least partly due to restoration of sensitivity of D1- and GABA-mediated mechanisms in the substantia nigra. It is interesting to see that both basic studies ${ }^{29.33}$ and clinical studies ${ }^{31.32}$ are demonstrating that it is the intermittent nature of DI stimulation which leads to changes and in the clinical situation, these changes ("on-off phenomena") are deleterious. This provides good sound reason for finding new formulations capable of providing continuous dopamine to the brain.

\section{D1 Dopamine Receptors and Gene Expression}

It has already been pointed out that animal studies suggest that it is D1 agonists rather than D2 agonists which produce dyskinesias. ${ }^{30}$ Similar clinical findings have been made. ${ }^{34} \mathrm{Dl}$ agonists and L-Dopa appear to selectively activate the immediate early gene $c$-fos in striatum, nucleus accumbens and other dopamine-innervated brain regions. ${ }^{35.36}$ Expression of $c$-fos and other immediate early genes is increased in mammalian neurons by a number of stimuli and the usefulness of this gene as a marker of neuronal activation has been demonstrated in several 
Table 1: Some Possible Associations Between Drug-induced Activation of the Immediate Early Gene c-fos and Pathophysiological Effects of Dopaminergic Drugs

\begin{tabular}{lll}
\hline \hline $\begin{array}{c}\text { Pathophysiological } \\
\text { Effect }\end{array}$ & $c$-fos Activator & Drug Class \\
\hline $\begin{array}{l}\text { dystonias } \\
\text { tardive dyskinesias } \\
\text { drug addition }\end{array}$ & $\begin{array}{l}\text { L-Dopa } \\
\text { haloperidol } \\
\text { amphetamine, } \\
\text { cocaine }\end{array}$ & $\begin{array}{l}\text { D1 dopamine agonists } \\
\text { D2 dopamine antagonists } \\
\text { indirect dopamine agonists }\end{array}$ \\
\hline
\end{tabular}

systems. ${ }^{37.38}$ Both directly-acting dopamine agonists of the DItype (SKF 38393, CY 208-243) ${ }^{35.36}$ and indirectly-acting dopamine agonists (amphetamine, cocaine) ${ }^{39,40}$ will produce a rapid and transient increase in Fos protein levels in varying patterns in striatum and cerebral cortex. The activation of $c$-fos by cocaine and amphetamine also appears to involve DI dopamine receptors preferentially. ${ }^{39.40}$ However, in contrast with indirectlyacting substances such as cocaine and amphetamine, directlyacting dopamine agonists (such as SKF 38393) only produce $c$ fos activation in denervated (supersensitive) striatum ${ }^{35.36}$ whereas cocaine and amphetamine activate $c-f o s$ in striatum in normal animals. ${ }^{39,40}$ Remarkably, D2 selective antagonists such as haloperidol also activate $c$-fos expression. ${ }^{4 l}$ In animals with 6-OHDA lesions, Dl-induced Fos is found in neurons which project to substantia nigra, ${ }^{42}$ again suggesting an association with neurons expressing only D! receptor. Thus, the development of dyskinetic movements following chronic drug treatments with either D1 agonists or D2 antagonists appear to be associated with activation of $c$-fos. It is possible then that longterm changes in gene expression regulated by immediate early genes may be an important step leading to development of these abnormalities of movement. Table 1 summarizes some longterm effects of dopaminergic drugs and possible relationship to c-fos activation.

\section{ACKNOWLEDGEMENTS}

The author's research has been generously supported by the Medical Research Council of Canada, The Human Frontiers Science Program, The Parkinson Foundation of Canada and Sandoz (Canada) Inc. I am grateful to Dr. Ann Graybiel for helpful discussion.

\section{REFERENCES}

1. Kebabian JW, Calne DB. Multiple receptors for dopamine. Nature $1979 ; 277: 93-96$

2. Sokoloff P, Giros B, Martres M-P, et al. Molecular cloning and characterization of a novel dopamine receptor (D3) as a target for neuroleptics. Nature 1990; 347: 146-151.

3. Ungerstedt U. Postsynaptic supersensitivity after 6-hydroxydopamine induced degeneration of the nigrostriatal dopamine system. Acta Physiol Scand 197I; 367 (Suppl): 69-101.

4. Cheramy A, Leviel V, Glowinski J. Dendritic release of dopamine in the substantia nigra. Nature $1981 ; 289: 537-542$.

5. Quik M, Emson PC, Joyce E. Dissociation between the presynaptic dopamine sensitive adenylate cyclase and $(3 \mathrm{H})$ spiperone binding sites in substantia nigra. Brain Res 1979; 167-335-365.

6. Murrin LC, Gale K, Kuhar MJ. Autoradiographic localization of neuroleptic and dopamine receptors in the caudate-putamen and substantia nigra: effects of lesions. Eur J Pharmacol 1979; 60: 229-235.

7. Boyson SJ, McGonigle P, Molinoff PB. Quantitative autoradiographic localization of the D1 and D2 subtypes of dopamine receptors in rat brain. $\mathrm{J}$ Neurosci 1986; 6: 3177-3188.
8. Savasta M, Dubois A, Benavides J, et al. Different neuronal location of $(3 \mathrm{H}) \mathrm{SCH} 23390$ binding sites in pars reticulata and pars compacta of the substantia nigra in the rat. Neurosci Lett 1986; 72: 265-271.

9. Missale C, Nisoli E, Liberini P, et al. Repeated reserpine administration up-regulates the transduction mechanism of $D$ receptors without changing the density of $(3 \mathrm{H}) \mathrm{SCH} 23390$ binding. Brain Res 1989; 483: 117-122.

10. Robertson GS, Robertson HA. Synergistic effects of D2 and D2 dopamine agonists on tuming behaviour in rats. Brain Res 1986; 384: 384-387.

11. Jackson DM, Hashizume M. Bromocriptine induces marked locomotor stimulation in dopamine-depleted mice when D- 1 dopamine receptors are stimulated with SKF 38393 Psychopharmacology 1986; 90: 147-153.

12. Rouillard C, Bedard PJ. Specific D1 and D2 dopamine agonists have synergistic effects in the 6-hydroxydopamine circling model in the rat. Neuropharmacology 1988; $27: 1257-1264$.

13. Sonsalla PK, Manzino L, Heikkila RE. Interactions of D1 and D2 dopamine receptors on the ipsilateral $\mathrm{vs}$ contralateral side in rats with unilateral lesions of the dopaminergic nigrostriatal pathway. J Pharmacol Exp Ther 1988; 247: 180-185.

14. Robertson HA, Robertson GS. Combined L-Dopa and bromocriptine therapy for Parkinson's disease: a proposed mechanism of action. Clin Neuopharmacol 1987; 10: 384-387.

15. Robertson GS, Robertson HA. DI and D2 dopamine agonist synergism: separate sites of action. Trends Pharmacol Sci 1987; 8: 295-299.

16. Clark D, White FJ. Review: DI dopamine receptor -- the search for a function: a critical evaluation of the DI/D2 dopamine receptor classification and its functional implications. Synapse 1987: 1: 347-388.

17. Robertson GS, Robertson HA. Evidence that the substantia nigra is a site of action for L-Dopa. Neurosci Lett 1988: 89: 204-209.

18. Robertson GS, Robertson HA. L-Dopa induced rotational behaviour is dependent on both striatal and nigral mechanisms. J Neurosci 1989; 9: 3326-3331.

19. Weick BG, Walters JR. Effects of DI and D2 dopamine receptor stimulation on the activity of substantia nigra pars reticulata neurons in 6-hydroxydopamine lesioned rats: D1/D2 coactivation induces potentiated responses. Brain Res 1987; 405: 234-246.

20. Aceves J, Floran B, Martinez-Fong D, et al. L-Dopa stimulates the release of $(3 \mathrm{H})$ gamma-aminobutyric acid in the basal ganglia of 6-hydroxydopamine lesioned rats. Neurosci Lett 1991; 121: 223226.

21. Trugman JM, Wooten GF. Selective D-1 and D-2 dopamine agonists differentially alter basal ganglia glucose utilization in rats with unilateral 6-hydroxydopamine substantia nigra lesions. J Neurosci 1987; 7: 2927-2935.

22. Hu X-T, Wachtel SR, Galloway MP, et al. Lesions of the nigrostriatal dopamine projection increase the inhibitory effects of DI and D2 dopamine agonists on caudate-putamen neurons and relieve D2 receptors from the necessity of D1 receptor stimulation. J Neurosci 1990; 10: 2318-2329.

23. LaHoste GJ, Marshall JF. Nigral D1 and striatal D2 receptors mediate the behavioral effects of dopamine agonists. Behav Brain Res 1990; 38: 233-242.

24. Spencer SE and Wooten GF. Pharmacologic effects of L-Dopa are not closely linked temporally to striatal dopamine concentration. Neurology 1984; 4: 1609-1611.

25. Zetterström T, Herrera-Marschitz M, Ungerstedt U. Simultaneous measurement of dopamine release and rotational behaviour in 6 hydroxydopamine denervated rats using intracerebral dialysis. Brain Res 1986; 376: 1-7.

26. Herrera-Marschitz $M$, Ungerstedt U. Evidence that striatal efferents relate to different dopamine receptors. Brain Res 1984; 323: 269-278.

27. Herrera-Marschitz $M$, Ungerstedt U. Effect of the dopamine D-1 antagonist SCH 23390 on rotational behaviour induced by apomorphine and pergolide in 6-hydroxydopamine denervated rats. Eur J Pharmacol 1985; 109: 49-54.

28. Graybiel AM. Neurotransmitters and neuromodulators in the basal ganglia. Trends Neurosci 1990; 13: 244-254. 
29. Gerfen CR, Engber TM, Mahan LC, et al. D1 and D2 dopamine receptor-regulated gene expression of striatonigral and striatopallidal neurons. Science 1990; 250: 1429-1432.

30. Bedard PJ, Di Paola T, Falardeau P, et al. Chronic treatment with levodopa but not bromocriptine induces dyskinesia in MPTPtreated monkeys. Correlation with ${ }^{3} \mathrm{H}$-spiperone binding. Brain Res 1986; 379: 294-299.

31. Moudranian MM, Juncos JL, Fabbrini G, et al. Motor fluctuations in Parkinson's disease: pathogenetic and therapeutic studies. Ann Neurol 1988; 22: 475-479.

32. Moudranian MM, Juncos JL, Fabbrini G, et al. Motor fluctuations in Parkinson's disease: central pathophysiological mechanisms, part II. Ann Neurol 1988; 24: 372-378.

33. Weick BG, Engber TM, Susel Z, et al. Responses of substantia nigra pars reticulata neurons to GABA and SKF 38393 in 6 hydroxydopamine-lesioned rats are differentially affected by continuous and intermittent levodopa administration. Brain Res 1990; 523: 16-22

34. Lees AJ, Stern GM. Sustained bromocriptine therapy in previously untreated patients with Parkinson's disease. J Neurol Neurosurg Psychiatry 1981; 44: 1020-1023.

35. Robertson GS, Herrera DG, Dragunow M, et al. L-Dopa activates c-fos expression in the striatum of 6-hydroxydopamine-lesioned rats. Eur J Pharmacol 1989; 159: 99-100.
36. Robertson HA, Peterson MR, Murphy K, et al. DI dopamine receptor agonists selectively activate striatal c-fos independent of rotational behaviour. Brain Res 1989; 503: 346-349.

37. Robertson HA, Dragunow M. From synapse to genome: the role of immediate-early genes in permanent alterations in the central nervous system. In: Osborne, NN, ed. Current Aspects of the Neuro-Sciences, 1990; 2: 143-157.

38. Robertson HA, Paul ML, Moratalla R, et al. Expression of the immediate early gene $c$-fos in basal ganglia: induction by dopaminergic drugs. Can J Neurol Sci 1991; 18: 380-383.

39. Graybiel AM, Moratalla R, Robertson HA. Amphetamine and cocaine induced drug-specific activation of the $c$-fos gene in striosome-matrix and limbic subdivisions of the striatum. Proc Natl Acad Sci USA 1990; 87: 6912-6916.

40. Young ST, Porrino LJ, Iadarola MJ. Cocaine induces striatal $c$-fosimmunoreactive proteins via dopaminergic Dl receptors. Proc Natl Acad Sci USA 1991; 88: 1291-1295.

41. Dragunow M, Robertson GS, Faull RLM, et al. Haloperiodol induces an accumulation of $c$-fos-like protein in rat striatal neurons: NMDA receptor mediation. Neuroscience 1990; 37: 287 294.

42. Robertson GS, Vincent SR, Fibiger HC. Striatonigral projection neurons contain D1 dopamine receptor-activated $c$-fos. Brain Res 1990; 523: 288-290. 